\title{
Steps towards Sustainability: Relationships between Neighborhood Environment and Physical Activity
}

\author{
Yasmeen Gul ${ }^{1}$, Gul A. Jokhio ${ }^{2, *}$, Zahid Sultan ${ }^{3}$ \\ ${ }^{1}$ College of Architecture and Design, AL Ghurair University, Dubai, UAE \\ ${ }^{2}$ College of Engineering and Information Technology, British University in Dubai, Dubai, UAE \\ ${ }^{3}$ Department of Civil \& Environmental Engineering, Botswana International University of Science and Technology, Botswana
}

Received June 8, 2021; Revised August 18, 2021; Accepted September 21, 2021

\section{Cite This Paper in the following Citation Styles}

(a): [1] Yasmeen Gul, Gul A. Jokhio, Zahid Sultan, "Steps towards Sustainability: Relationships between Neighborhood Environment and Physical Activity," Environment and Ecology Research, Vol. 9, No. 6, pp. 315 - 329 , 2021. DOI: 10.13189/eer.2021.090601.

(b): Yasmeen Gul, Gul A. Jokhio, Zahid Sultan (2021). Steps towards Sustainability: Relationships between Neighborhood Environment and Physical Activity. Environment and Ecology Research, 9(6), 315 - 329. DOI: 10.13189/eer.2021.090601.

Copyright $\mathrm{C} 2021$ by authors, all rights reserved. Authors agree that this article remains permanently open access under the terms of the Creative Commons Attribution License 4.0 International License

\begin{abstract}
Physical activity (PA) is pivotal for health, and Neighborhood Environment (NE) is understood to play a significant role in increasing physical activity. The investigation into the combined effects of $\mathrm{NE}$ on PA considering the differences between gated and non-gated types of neighborhoods in developing countries is relatively scarce. As an effort towards filling this gap, this paper reports an investigation that focuses on the association of PA with NE; moreover, it compares the PA in gated and non-gated neighborhoods in Karachi, Pakistan. Data were calculated through objective and subjective methods. 8 out of 16 neighborhoods were gated. 499 out of total 1042 participants were from the gated neighborhoods. Partial correlation and binary logistic regression analyses were carried out. The effects of age, gender, and employment status were controlled for the purpose of statistical analysis. Positive relationships were identified between walking and street connectivity and land-use mix. The relationship between walking and housing density was negative. The number of physical activity facilities (PAF) was found to positively influence vigorous physical activity (VPA). It was noted that there were more PAF in gated neighborhoods, hence an enhanced VPA there, but only among young age group people. Therefore, it has been concluded that new policies for neighborhoods design should be formulated to provide multiple choices for every individual so that they can achieve the required levels of physical activity.
\end{abstract}

Keywords Asian Developing Countries, Physical Activity, Gated Neighborhoods, Physical Activity Facilities, Neighborhood Built Environment

\section{Introduction}

To achieve desirable health outcomes, the World Health Organization (WHO) emphasizes the significance of the maintenance of recommended Physical Activity (PA) levels. Several health organizations have formulated recommendations for achieving the required PA levels, for example, the guidelines by WHO, and those by the American Heart Association (AHA). The key guidelines by WHO related to PA of adults (18-65) are: Achieve 600 MET minutes a week through either 30 min moderate PA (MPA) 5 days, or alternatively, 20 min vigorous PA (VPA) 3 days [1]. The VPA is accomplished by means of physically demanding sports such as football, fast paced running, or gym workouts etc. MPA, on the other hand, can be achieved via less intensive activities such as brisk walking. [2]. Walking can be dichotomized into recreational walking or practical walking depending upon the purpose. Walking for transportation or any other utility purpose such as going to the shops is termed as practical walking, whereas the purpose of recreational walk can be health benefits or leisure [3]. The specified 
MET values for VPA, MPA, practical, and recreational walking; are $8,5.5,4$, and 3.5 ; respectively $[1,4]$. Neighborhood Environment (NE) is considered important to affect PA and it has recently attained the status of a desirable area of research by the experts of Urban and Transportation Planning [5] and Public Health [6].

Two different types of methods can be used to quantify PA; these include objective measurement using instruments, and subjective measurement using questionnaires. Two instruments i.e. accelerometer and pedometer have been most widely used for the objective measurement of PA $[7,8]$. For measuring PA using the subjective methods, two of the most widely used standard questionnaires are; International Physical Activity Questionnaire (IPAQ) [9], and Neighborhood Physical Activity Questionnaires (NPAQ) [10]. The IPAQ is considered the most-reliable [11], whereas, NPAQ has also been considered a reliable questionnaire, which asks the respondents to recall the names of places they visit in a usual week [3].

Neighborhood environment (NE) has been mainly defined as consisting of built and social environments, and the availability of PAF, for affecting physical activity [12]. The primary indicators of built environment of a neighborhood are the land-use patterns. Land-use mix has been found to be correlated with moderate level of PA [13, 14]. A systematic review also showed that there is a relationship between NE along with weight status. The American studies were taken for the review and the results showed that there is consistently a correlation between urban sprawl and land-use mix with weight status, but only in North America [15]. Whereas, in another study, it was counterintuitively found that the increase in land-use mix resulted in less PA in Detriot [16]. Street connectivity, which is also one of the important indicators of neighborhood built environment, has also been found correlated with PA because it encourages more practical walking [17]. It has been reported in literature that housing density is correlated with different types of PA such as practical walking $[18,19]$. Similarly, a review of the use of smart growth planning showed that five indicators are important for PA, mainly for walking; the indicators include diverse housing types, land-use mix, housing density, compact development patterns, and open space [20]. Another study exclusively in the association of residential density with adiposity outcomes showed that there is a positive association between residential density and PA and negative association with BMI [21].

Accessibility is the second important part of neighborhood built environment, and it is measured by accessibility to facilities and infrastructure availability. It was found in the literature that accessibility to facilities and infrastructure availability was important to encourage people to be physically active at neighborhood level through walking and cycling [22]. At policy level, it was noticed that physical health has been taken into account while designing of neighborhoods in a review of Australian context, which concluded that neighborhood designs should include walkability-inducing infrastructure and the availability of walking destinations in the development or redevelopment of urban areas to keep the residents physically active [23]. Another review of the use of COCOMO strategies in the rural areas of America and Canada for the PA in children and youth also showed that improvement in infrastructure availability has improved the walking and cycling in rural children [24]. Similarly, in another review, it was found that there is a positive association of improvement of transportation infrastructure with practical walking [25]. Along with accessibility, the design features are considered important to increase PA at neighborhood level. Design features are measured through aesthetics and streetscape [26]. Aesthetics of a neighborhood include landscaping and building facades, etc.; while streetscape includes the availability of street furniture, street lights, trees along pathways in streets, etc. All these indicators have been found important to increase recreational walking at neighborhood level [22].

The social environment (safety indicators) of a neighborhood are; the perception of crime, traffic hazards, and physical disorders (i.e. litter, tagging, and graffiti etc.). The higher values of these indicators have negative association with PA [27,28]. Similarly, physical disorder, such as littering/vandalism/decay, was also found to be negatively related to total walking for transport [29]. Along with the safety indicators, the provision of physical activity facilities (PAF) is also considered important for enhancing PA at neighborhood level, as concluded by public health literature [30], especially the vigorous physical activity $[31,32]$.

The influence of Socio-demographical variables such as age, gender, income, education level, and marital status have also been investigated in different studies on physical activity; for example, age was found negatively associated with PA [33]. Women were found less physically active compared to men [34], high income group people were found more physically active, specially vigorously active for physical fitness; and low income group people were found physically active for utility purposes such as for practical walking [35].

The hierarchy of NE indicators that can affect PA is presented in Figure 1. 


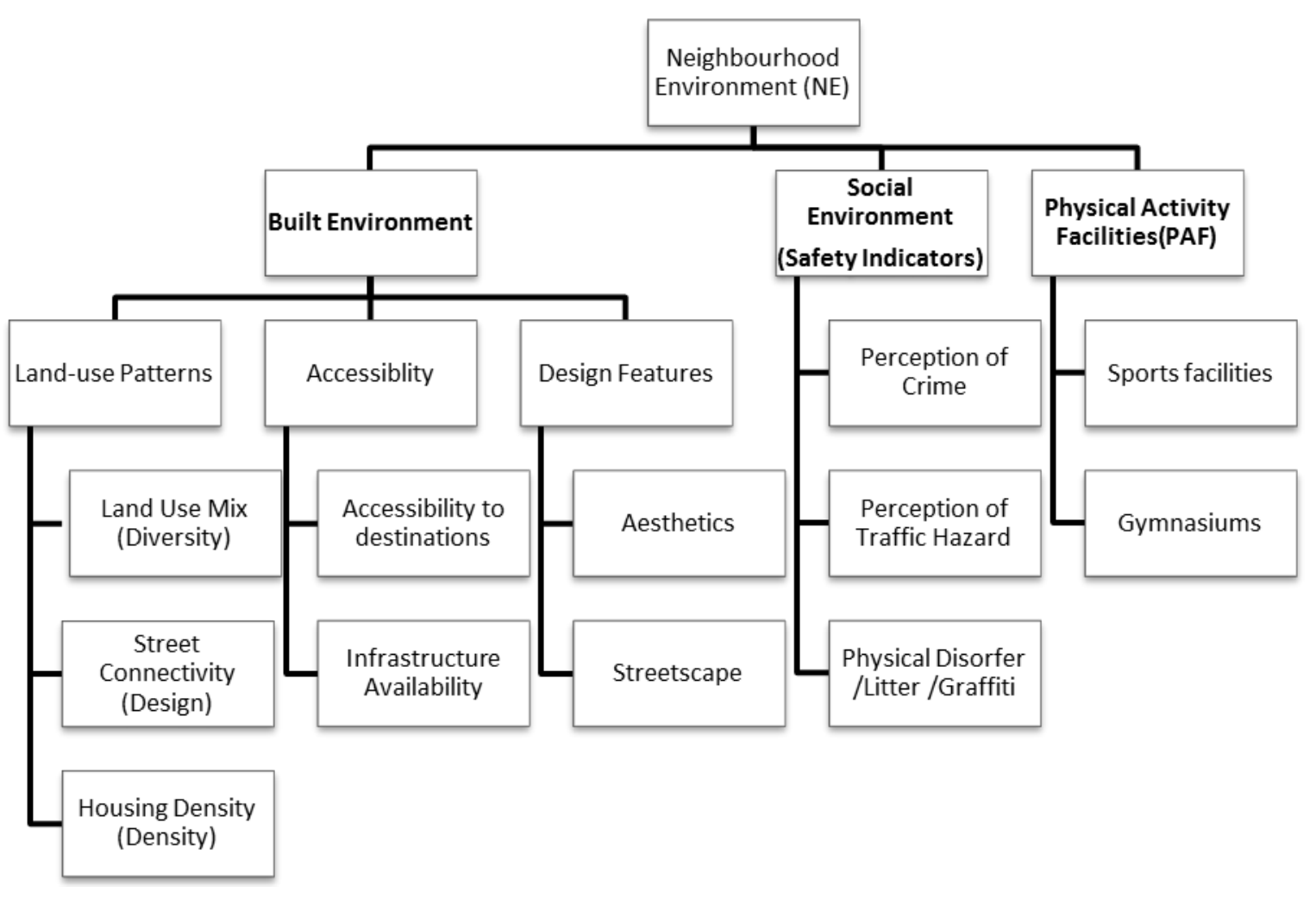

Figure 1. Hierarchy of NE indicators

The studies referred to above were conducted mainly in developed countries such as the USA, Europe, Canada, and Australia. There have been conducted some studies beyond developed countries, for example, a study consisting of the comparison of 14 diverse cities from different countries investigated the associations of land-use mix, connectivity given by intersections density, housing density, and number of parks in a $1 \mathrm{~km}^{2}$ area with walking and cycling. The researchers concluded that the land-use had linear association with walking while intersection density and housing density had association with cycling [36]. Another comparison of perceived indicators of NE with accelerometer-measured-transportation walking in 16 different cities from 11 developed as well as developing countries was carried out. The results showed that most of the NE indicators had positive association with transportation PA [37]. Similarly, the older adults $(+65)$ in Hong Kong were found to do four times higher recreational walk than the older adults of Western countries. The indicators considered were recreational facilities proximity, the availability of indoor as well as outdoor walking facilities, and the presence of connecting bridge/overpasses to services [38]. In a cross sectional study of 11 countries, the NE indicators were investigated along with PA and the results showed that the mixed land-use and infrastructure availability were the most significant contributors towards the achievement of recommended PA. Moreover, the availability and accessibility of public transit, recreational facilities that are free or have nominal charges, and the availability of bike facilities had correlations with PA, but not with the same consistency in all the countries. The causes of less bicycling were investigated in Beijing, China and it was concluded that the drastic changes in NE have decreased the use of bicycles in China. The results showed that the use of bicycle was positively influenced by a greater number of exclusive bike lanes and a better connectivity between local streets in Beijing. On the other hand, housing density did not significantly affect the cycling activity, which was reduced as a result of the availability of better public transit services [39]. In another comparative study between urban and rural adults from a developing country, South Africa, showed that after adjusting for gender and age, the proximity to local stores was significantly associated with the practical walking; whereas, the proximity to pleasant scenery, sidewalks, shade from trees, traffic, and well-lit streets were significantly associated with walking for leisure [40] Another study of the perceived NE indicators with recreational walking was carried out in 12 countries and the results showed that recreational walking had a linear correlation with the availability of nearby parks, lower hazard perceptions, appealing aesthetics, better street connectivity and a good mix of the land-use. The findings of that study suggested that comparable environmental characteristics are linked with recreational walking internationally [41]. The results of a study from Hong Kong investigating the effects of 3D's (design, density and diversity) on walking suggested that the effects may 
vary in different urban contexts because their results showed that there is an association between design and diversity with walking but there is no association between density and walking [42]. The review of the effects of perceived NE indicators on walking for transportation, work, and recreation among adults in major cities of China showed that the proximity of non-residential walking destinations, aesthetic and pedestrian friendly infrastructure and PA facilities had the strongest positive associations with walking whereas the opposite association was reported with the density of urban residences [43].

Most of the studies reported above have investigated the NE for PA but few studies have exclusively addressed the effects of the relatively newer and fast emerging form of neighborhood design, the Gated neighborhoods, on PA. This type of neighborhood is generally isolated from the rest of the city by means of walls and fences [44]. These neighborhoods are considered to have more PAF, lower perceptions of crime and traffic hazards, less mix of the land-use, less street connectivity, and low housing density compared to non-gated neighborhoods [32]. The practice of adding walls and gates to neighborhoods is rapidly growing in Asia, especially in the developing countries [45]. It has been found that the trend of gated neighborhoods is also on the rise in Karachi, Pakistan and by 2030 , it is estimated that $50 \%$ of neighborhoods will be gated for safety and healthy lifestyles purposes [46].

The above discussion on the available literature leads to the objective of the study being reported here, which is an investigation that focuses on the correlation between NE indicators and PA variables and compares it in gated and non-gated neighborhoods in the developing countries in Asia with the data collected from Karachi, Pakistan. A secondary objective of the present study is to evaluate the effectiveness of the gated neighborhoods in view of the claim generally made by the promoters of these types of developments that these provide a safer environment and facilities that are more conducive to physical activity.

\section{Methods}

\section{Study Location}

The present study was cross-sectional in nature carried out by comparing gated with equivalent non-gated neighbourhoods in Karachi, Pakistan. It was carefully chosen as the study location because with an urban area of $3,527 \mathrm{~km}^{2}$, it is one of the biggest metropolises [47], among Asian developing countries [48], and has a heterogeneous population because of heavy migration of job seekers along with their families from different backgrounds from all over the country [49]. Karachi, just like any other Asian mega metropolis, has both planned and unplanned neighborhood types. The planned neighborhoods can be dichotomized into single-unit and multi-unit types. The multi-unit developments include walk-ups (i.e. buildings not exceeding 5 levels, which do not require the installation of an elevator by law) or high-risers (normally up to 16 levels in Karachi which require an elevator by law). Again, similar to any other Asian mega metropolis, the trend of gated neighborhoods is on the rise in Karachi [50]. Administratively, Karachi is divided into 5 districts and 2 cantonments. The districts are conveniently named as South, East, Central, West, and Malir. The South and West districts were excluded from this study owing to there being gated neighborhoods. The Base Map of selected neighborhoods for this study is given in Figure 2.

For selecting neighborhoods, four factors were taken into account, which are listed below:

Development Type: From three districts and 2 cantonments of Karachi, four neighborhoods of each type i.e. single-unit and multi-unit, gated and non-gated were nominated, which yielded a total of 16 neighborhoods.

Income Group: The residents of the nominated neighborhoods were from the income groups of middle to high levels ( $\$ 650$ to $\$ 2500$ per month). This income group was selected because gated neighborhoods mostly belong to this group; therefore, the corresponding non-gated neighborhoods were also chosen from the same income groups. It is worth noting here that the socio-economic conditions of the inhabitants greatly affect the physical activity behavior in that area, as reported in literature [35]. Therefore, it is expected that if neighborhoods from lower income groups were studied, much less participation would be recorded in sports or leisure activities, whereas, a remarkably higher participation would be expected in utility based physical activity. However, since the basic purpose of the present study was to compare the gated and non-gated neighborhoods and evaluate the effectiveness of gated neighborhoods as places with greater physical activity, all the selected neighborhoods were relatively wealthier.

Population Density: The product of the gross housing density of each neighborhood and the specified average household size in the city was deemed as the population density [47]. It was taken care that the gross populations of the selected neighborhoods were closely matched.

Area: It was aimed that the size of the selected neighborhoods in terms of area be as close to $1 \mathrm{~km} 2$ as possible. This number was chosen as it is considered the convenient size of the neighborhood from the point of view of accessible walking destinations.

The selection criteria for the 16 neighborhoods ( 8 of the each type i.e. gated and non-gated) for this study were in line with the studies of $[18,51,52]$. The names, area, location and population density of all 16 neighborhoods are given in Table 1. 


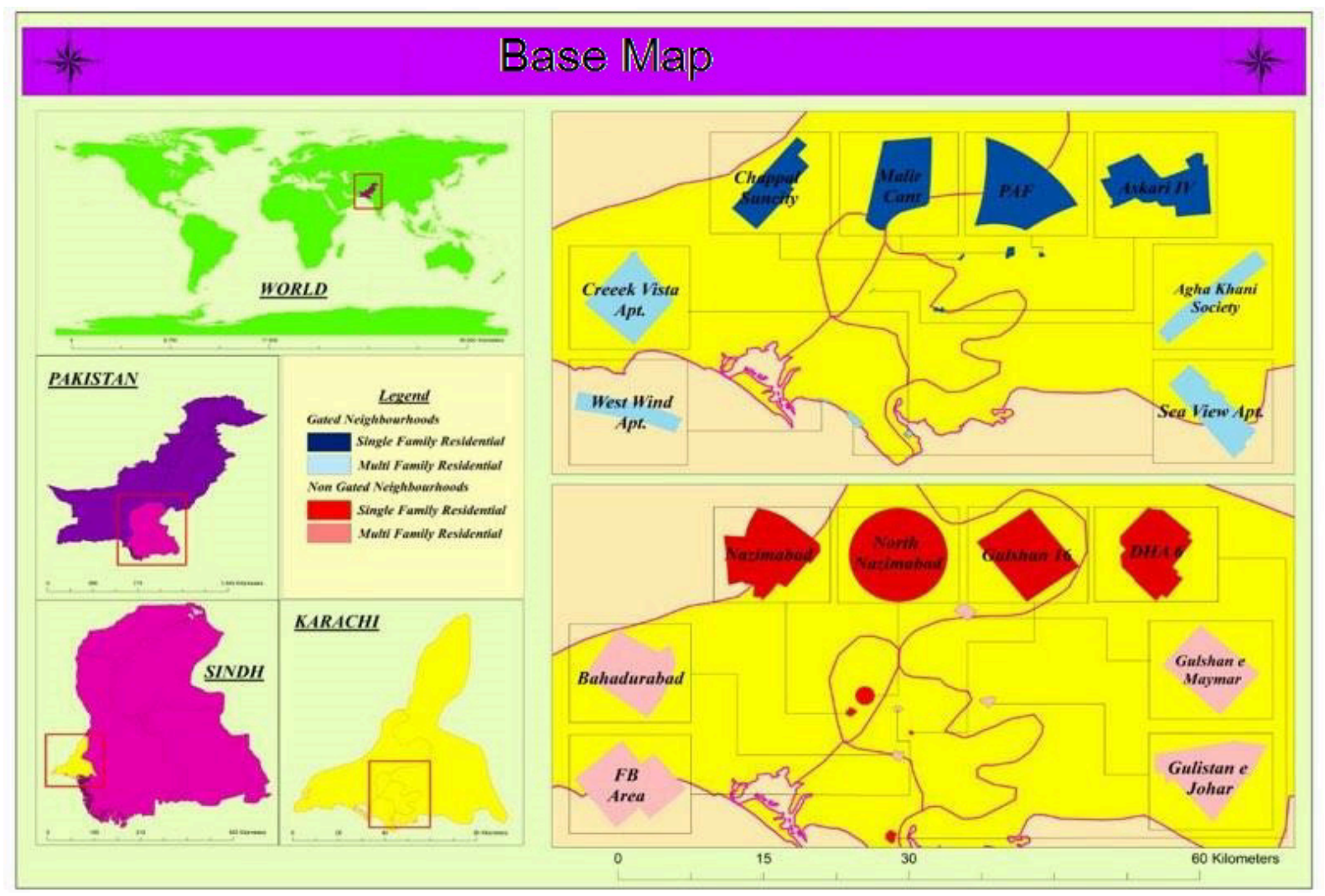

Figure 2. Base Map for of selected neighborhoods

Table 1. Details of Selected neighborhoods

\begin{tabular}{|c|c|c|c|c|c|c|c|c|c|}
\hline \multicolumn{4}{|c|}{ Gated Neighborhoods } & \multicolumn{4}{|c|}{ Non-Gated Neighborhoods } & \multirow[b]{2}{*}{$\begin{array}{c}\text { Development } \\
\text { Type }\end{array}$} & \multirow[b]{2}{*}{$\begin{array}{l}\text { Income } \\
\text { Group }\end{array}$} \\
\hline Name & $\begin{array}{c}\text { Area } \\
\text { in } \\
\mathrm{K} 2 \mathrm{~m} \\
\end{array}$ & Location & $\begin{array}{l}\text { Population } \\
\text { density }\end{array}$ & Name & $\begin{array}{c}\text { Area } \\
\text { in } \\
\mathrm{K} 2 \mathrm{~m}\end{array}$ & Location & $\begin{array}{l}\text { Population } \\
\text { density }\end{array}$ & & \\
\hline $\begin{array}{c}\text { Malir } \\
\text { Cantonment }\end{array}$ & 1.0 & Cantonments & 9,380 & $\begin{array}{l}\text { Gulshan-e- } \\
\text { Maymar }\end{array}$ & 1.0 & District Malir & 8,040 & Single-unit & $\begin{array}{c}\text { Upper } \\
\text { middle } \\
\text {-High }\end{array}$ \\
\hline $\begin{array}{l}\text { PAF Falcon } \\
\text { Housing } \\
\text { Society }\end{array}$ & 0.5 & Cantonments & 4,225 & $\begin{array}{c}\text { DHA } \\
\text { Phase-VI }\end{array}$ & 0.5 & Cantonments & 5,440 & Single-unit & $\begin{array}{l}\text { Upper } \\
\text { middle } \\
\text {-High }\end{array}$ \\
\hline $\begin{array}{l}\text { Chapal } \\
\text { Suncity }\end{array}$ & 0.5 & District East & 14,657 & $\begin{array}{c}\text { North } \\
\text { Nazimabad } \\
\text { Blocks } \\
\text { C,D,E }\end{array}$ & 1.0 & $\begin{array}{l}\text { District } \\
\text { Central }\end{array}$ & 17,018 & Single-unit & $\begin{array}{l}\text { Upper } \\
\text { middle }\end{array}$ \\
\hline $\begin{array}{c}\text { Askari } \\
\text { Phase-IV }\end{array}$ & 0.5 & Cantonments & 12,294 & $\begin{array}{c}\text { Nazimabad } \\
\text { Block-5 }\end{array}$ & 1.0 & $\begin{array}{l}\text { District } \\
\text { Central } \\
\end{array}$ & 11,564 & Single-unit & $\begin{array}{l}\text { Upper } \\
\text { middle }\end{array}$ \\
\hline $\begin{array}{l}\text { Creek Vista } \\
\text { Apartments }\end{array}$ & 0.5 & Cantonments & 12,641 & $\begin{array}{c}\text { Bahadarabad } \\
\text { Chowrangi }\end{array}$ & 1.0 & Cantonments & 11,932 & $\begin{array}{l}\text { Multi-unit } \\
\text { High rises }\end{array}$ & $\begin{array}{c}\text { Upper } \\
\text { middle } \\
\text {-High }\end{array}$ \\
\hline $\begin{array}{l}\text { West Wind } \\
\text { Apartments }\end{array}$ & 0.5 & Cantonments & 11,725 & $\begin{array}{l}\text { Gulistan-e- } \\
\text { Johar }\end{array}$ & 1.0 & Cantonments & 15,845 & $\begin{array}{l}\text { Multi-unit } \\
\text { High rises }\end{array}$ & $\begin{array}{l}\text { Upper } \\
\text { middle } \\
\text {-High }\end{array}$ \\
\hline $\begin{array}{l}\text { Sea View } \\
\text { Apartments }\end{array}$ & 1.0 & Cantonments & 11,457 & $\begin{array}{c}\text { Gulshan-e- } \\
\text { Iqbal } \\
\text { Block-16 }\end{array}$ & 0.5 & District East & 12,878 & $\begin{array}{l}\text { Multi-unit } \\
\text { Walk-ups }\end{array}$ & $\begin{array}{l}\text { Upper } \\
\text { middle }\end{array}$ \\
\hline $\begin{array}{l}\text { Agha Khani } \\
\text { Housing } \\
\text { Society }\end{array}$ & 0.5 & District East & 17,118 & $\begin{array}{l}\text { FB Area } \\
\text { Block-3 }\end{array}$ & 0.4 & District East & 17,108 & $\begin{array}{l}\text { Multi-unit } \\
\text { walk-ups }\end{array}$ & $\begin{array}{l}\text { Upper } \\
\text { middle } \\
\text {-High }\end{array}$ \\
\hline
\end{tabular}




\section{Study Sample}

A multi-stage cluster sampling strategy was employed in this study after slightly modifying it. According to this technique, the target population is divided into clusters considered to represent the different characteristics of the entire populations. One or more clusters are then chosen at random and maximum inhabitants of that cluster are surveyed. For the purpose of this study, however, the technique was slightly modified.

For modified multi-stage cluster sampling approach, the target population of the present study consisted of two types of neighborhoods; gated, and non-gated. These neighborhoods were divided into smaller manageable areas such as residences near commercial areas, residences near public building (i.e. schools and mosques) areas, and residences near recreational (i.e. public parks) areas. These smaller neighborhood blocks were considered as clusters for the sampling purpose. However, since these areas tended to represent different characteristics of the neighborhoods, the overall picture about the neighborhoods could only emerge if data was obtained for all of these clusters. The random selection of clusters, therefore, was not advisable in the present study. However, the time and resource limitations required that random sample selection had to be imposed at some stage.

A criterion sampling was used in the present study, which was done at a higher level. Instead of the clusters, the inhabitants of a cluster were chosen randomly and data was collected that represented the different characteristics of that particular cluster. Thus when the data representing all the clusters was compiled and analyzed, the full picture about the gated and non-gated neighborhoods emerged. The criterion sampling within a cluster consisted of the criteria of the ability of 18-65 year old respondents to complete or understand the survey and the absence of any disability preventing them from doing PA. The above selection criteria notwithstanding, it was attempted to sample one person per house.

Minimum required sample size was 384 individuals in each types of neighborhoods, i.e. 768 in total. However, this study has used over sampling of 75 individuals from each neighborhood; which is in line with some previous studies $[14,18,53]$. The final sample size after exclusion of missing data was 1042. The training sessions were conducted by the first author during the Urban Planning studio with the help of the class teacher. The first author also monitored the whole survey process.

\section{Study Variables}

\section{Dependent Variables}

Total four physical activity variables were calculated through subjective methods (2 questionnaires). The physical activity variables VPA and MPA were collected through International Physical Activity Questionnaire (IPAQ-short) [54]. The survey respondents were first asked if they had done any vigorous physical activity such as any physically demanding sports activities, or gym workouts in the preceding 7 days; and if yes, how many minutes each day and how many days each week they did that activity. MPA was measured through questions related to moderate activities, for example, brisk walking, cycling, or other light physical exertion in the preceding week and, similarly, the duration and days per week were recorded. Walking was divided into two types i.e. walking for any utility, and walking for leisure; and was computed by means of the Neighborhood Physical Activity Questionnaire (NPAQ) [55]. The reason for using NPAQ was that it was comfortable for participants to recall the name of the area instead of just recalling the walking activity at neighborhood level in the preceding seven days. The questions used to assess walking asked whether in the preceding 7 days they had walked around the neighborhood for utility or leisure purposes. The destination options for practical walking were schools, mosques, work, public transport, and shops. The destination options for recreation walking were parks, friends' or relatives' houses, cafés, walk on pathways and trails of neighborhoods just for pleasure without any destination, and others (this needed to be specified by the respondents). All physical activity durations per week were then multiplied by the relevant MET values [4]. The physical activity variables with the corresponding MET values are given in Table 2 .

Table 2. Description of PA variables /Dependent Variables

\begin{tabular}{|c|c|c|c|}
\hline PA Variables & Questionnaire & $\begin{array}{c}\text { Specified } \\
\text { MET Value }\end{array}$ & Description \\
\hline Aggregate PA & & & The total of VPA, MPA, and the aggregate walking. \\
\hline $\begin{array}{l}\text { Vigorous physical } \\
\text { activity (VPA) }\end{array}$ & $\begin{array}{l}\text { IPAQ-Short } \\
\text { Form }\end{array}$ & 8 & $\begin{array}{l}\text { Physically intensive activities that raise the heart rate to a high level } \\
\text { ( } 70-85 \% \text { of maximum heart rate) }\end{array}$ \\
\hline $\begin{array}{l}\text { Moderate physical } \\
\text { activity (MPA) }\end{array}$ & $\begin{array}{l}\text { IPAQ-Short } \\
\text { Form }\end{array}$ & 5.5 & $\begin{array}{l}\text { Moderately intensive physical exertion that raises the heart rate to a } \\
\text { considerable level }(50-70 \% \text { of maximum heart rate) }\end{array}$ \\
\hline Aggregate Walking & & & The sum of utility and recreational walking \\
\hline Practical Walk & NPAQ & 4 & $\begin{array}{l}\text { Walking for a specific utility, for example, going to the shops or to a bus } \\
\text { stop, etc. }\end{array}$ \\
\hline Recreational Walk & NPAQ & 3.5 & Walking only for the purpose of health benefits or for leisure \\
\hline
\end{tabular}




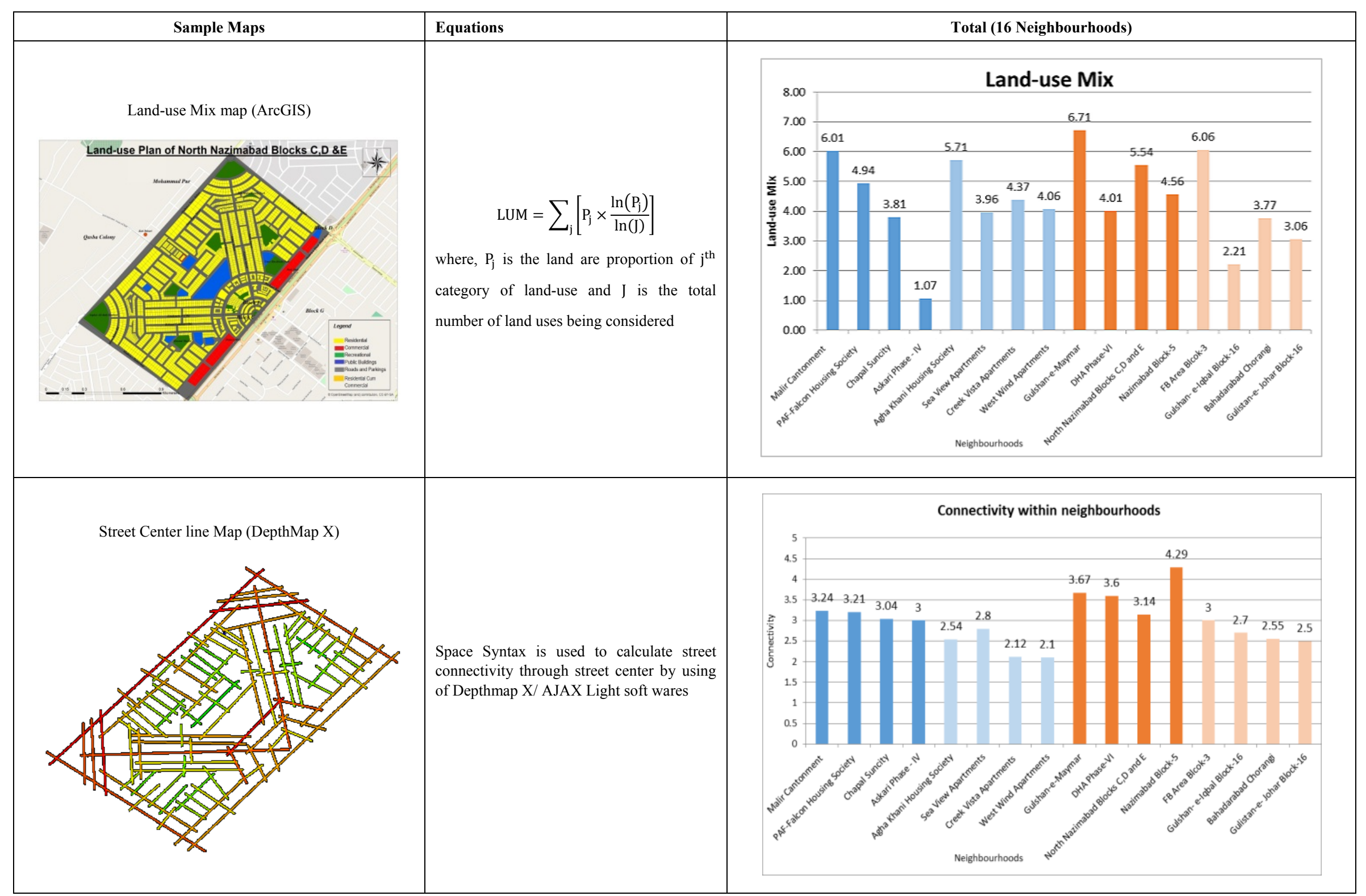




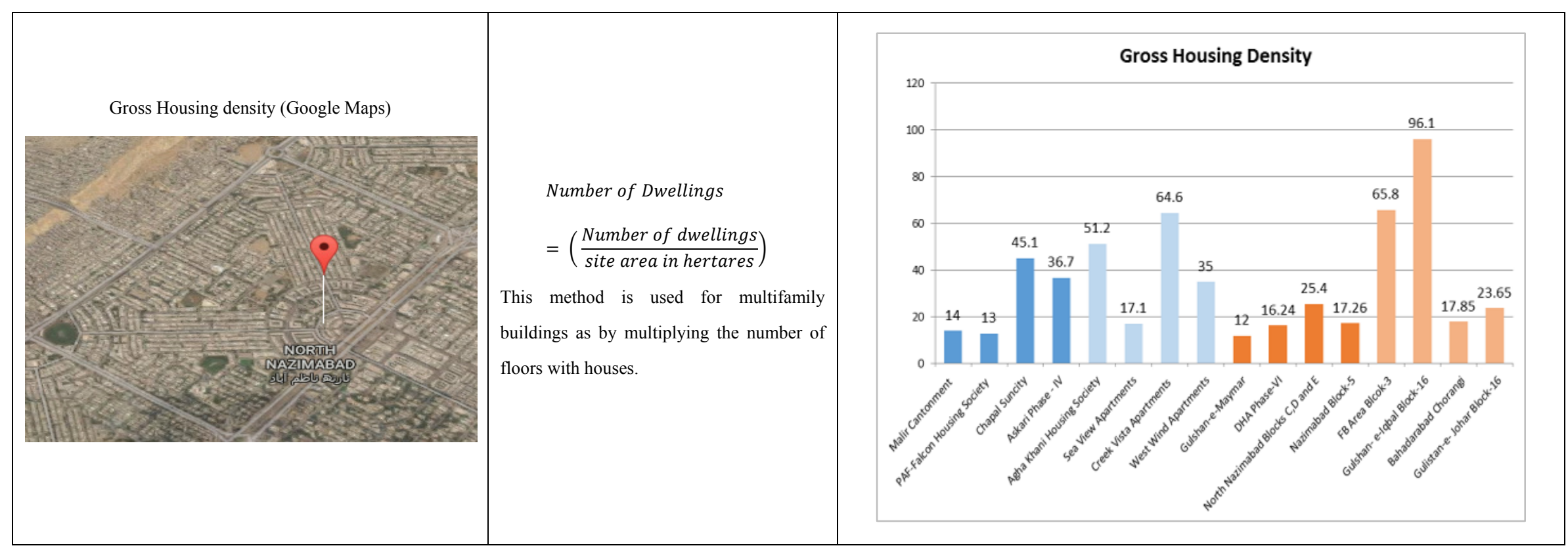

Figure 3. Objective method of data collection for housing density, street connectivity, and land-use mix (LUM) 


\section{Neighborhood Environment Parameters}

A total of six NE parameters were nominated as independent variables for this investigation. The $\mathrm{NE}$ indicators were divided into three categories: built environment, social environment (safety indicators), and physical activity facilities; and were calculated through different methods. The built environment indicators comprising land-use mix (LUM), street connectivity, and housing density were calculated with the help of aerial maps of the neighborhoods provided by the concerned development authorities. Aerial maps were then translated into GIS using ArcGIS. LUM was computed by means of entropy index, which calculates the distribution of 4 types of land-uses i.e. residential, commercial, recreational and public buildings (such as schools, mosques, hospitals, community centers etc.). The use of entropy index was based on previous studies reported in the literature [56,57]. The scale used for LUM was from 0-1 where 1 showed a complete mix of all types of land-uses and 0 showed the least mix of land-uses (effectively a single type of land-use). Street connectivity was measured through street center line maps with Space Syntax (Depthmap X and AJAX-Light) method. This process provided the axial maps in different colors and values to show connectivity of streets. The average connectivity values were then used for further statistical analysis in SPSS. Gross density given as number of houses per hectare was used as a measure of housing density. Less than 17 houses per 100 hectare was categorized as low, 17-45 as medium, and greater than 45 houses per 100 hectare as high density [58]. The maps and equations for calculating LUM, street connectivity and housing density are given in Figure 3.

Physical Activity facilities (PAF) such as sports facilities (i.e. football grounds, cricket grounds, tennis courts, badminton courts, swimming pools, and dance halls) and number of gymnasiums were counted by trained surveyors on site. The PAF that were found out of service during screening were excluded from this study. The hazard perceptions of crime traffic were measured using the 4 point Likert scale based Neighborhood Environment Walkability Scale (NEWS) [59]. The questions, which were used to measure perception of crime, asked whether the respondents felt safe while walking around their neighborhood; and whether they saw other people walking or on bikes in their street while walking. Two questions were asked related to traffic hazard perception; whether they felt the speed of traffic was high in their streets, and secondly, whether the traffic hindered their walk.

\section{Socio-demographics/Control Variables}

Age, gender, and employment status were used as control variables in this study. Four age groups of 18-30, 31-40, 41-50, and 51-65 were used. For the employment status purpose, housekeepers were included in the non-employed category whereas people with a government/private job and those with self-employment were included in the employed category. Similarly, retired people, students, or people without a job/business were included in the un-employed category.

\section{Statistical Analysis}

The comparative statistical analysis of NE indicators and PA variables in detail was done somewhere else [32]. This paper shows the relationships of NE indicators and $\mathrm{PA}$ variables as well as the relationship of $\mathrm{NE}$ indictors with aggregate PA (greater than $600 \mathrm{MET} /$ week). The first part of analysis shows the relationships of NE indicators with PA variables through partial correlation, while the effects of gender, employment status, and age were controlled. At second level, the effects of NE indicators and socio-demographics were investigated on recommended level of PA (i.e. 600 MET minutes in a week) through binary logistic regression analysis. Physical activity variables including VPA, MPA, practical, and recreational walking were added to get aggregate PA and then it was dichotomized into people who get more than 600 MET in a week or less than 600 MET in a week through binary logistic regression. The differences in PA have also been investigated in gated and non-gated neighborhoods through binary logistic regression.

\section{Results}

\section{Relationships between Neighborhood Environment (NE) Indicators and Physical Activity (PA) Variables}

The relationship between NE indicators and PA was studied through the data analysis while controlling the effects of age, gender, and employment status. From the results, it can be seen that practical walking is positively correlated with land-use mix (LUM). Both the practical and the recreational walking are positively correlated with street connectivity. It is apparent that the vigorous physical activity (VPA) is correlated positively only with the availability of physical activity facilities (PAF). On the other hand; housing density and crime and traffic hazard perceptions have significant negative relationships with PA variables. The most significant correlation has been found between PAF and VPA. The results suggest that all NE indicators have relatively small effect but significant relationships with one or more of the variables comprising PA in both the types of neighborhoods in Karachi i.e. gated and non-gated. These results have been summarized in Table 3. 
Table 3. Results of the partial correlation analysis

\begin{tabular}{|c|c|c|c|c|c|c|}
\hline \multirow{2}{*}{ Control Variables } & \multirow{2}{*}{ NE indicators } & \multirow{2}{*}{ Relationships } & \multicolumn{4}{|c|}{ PA Variables } \\
\hline & & & VPA & MPA & Practical Walk & Recreational Walk \\
\hline \multirow{12}{*}{$\begin{array}{l}\text { Age \& Gender \& } \\
\text { Employment Status }\end{array}$} & \multirow{2}{*}{ Land-Use Mix } & Correlation & -.012 & -.013 & .184 & .018 \\
\hline & & Significance (2-tailed) & .715 & .681 & .000 & .584 \\
\hline & \multirow{2}{*}{ Street Connectivity } & Correlation & .061 & .002 & .144 & .078 \\
\hline & & Significance (2-tailed) & .059 & .943 & .000 & .016 \\
\hline & \multirow{2}{*}{ Housing Density } & Correlation & .064 & .014 & -.088 & -.130 \\
\hline & & Significance (2-tailed) & .311 & .819 & .163 & .039 \\
\hline & \multirow{2}{*}{$\begin{array}{l}\text { Physical Activity } \\
\text { Facilities }\end{array}$} & Correlation & .179 & .041 & .191 & .089 \\
\hline & & Significance (2-tailed) & .000 & .205 & .000 & .006 \\
\hline & \multirow{2}{*}{ Perception of Crime } & Correlation & -.106 & .007 & -.036 & -.031 \\
\hline & & Significance (2-tailed) & .001 & .827 & .265 & .337 \\
\hline & \multirow{2}{*}{$\begin{array}{c}\text { Perception of Traffic } \\
\text { Hazard }\end{array}$} & Correlation & -.045 & -.020 & -.081 & .032 \\
\hline & & Significance (2-tailed) & .164 & .543 & .012 & .320 \\
\hline
\end{tabular}

Table 4. Association of NE Indicators, Socio-demographical factors with aggregate PA

\begin{tabular}{|c|c|c|c|c|c|c|c|c|}
\hline \multirow{3}{*}{$\begin{array}{l}\text { NE Indicators and } \\
\text { socio-demographics }\end{array}$} & \multicolumn{8}{|c|}{ Aggregate PA (Dichotomized into $<600 \mathrm{MET}$ and $>600 \mathrm{MET}$ ) } \\
\hline & \multirow{2}{*}{ B } & \multirow{2}{*}{ S.E. } & \multirow{2}{*}{ Wald } & \multirow{2}{*}{ df } & \multirow{2}{*}{ Sig. } & \multirow{2}{*}{$\operatorname{Exp}(B)$} & \multicolumn{2}{|c|}{ 95\% C.I.for EXP(B) } \\
\hline & & & & & & & Lower & Upper \\
\hline Land-use mix & .278 & .114 & 5.936 & 1 & .015 & 1.321 & 1.056 & 1.653 \\
\hline Street Connectivity & .207 & .115 & 3.247 & 1 & .072 & 1.230 & .982 & 1.542 \\
\hline Housing density & -.009 & .003 & 8.767 & 1 & .003 & .991 & .985 & .997 \\
\hline PAF & .672 & .145 & 21.616 & 1 & .000 & 1.959 & 1.475 & 2.601 \\
\hline Perception of Crime & -.043 & .062 & .475 & 1 & .491 & .958 & .849 & 1.082 \\
\hline Perception of Traffic hazard & -.100 & .059 & 2.830 & 1 & .093 & .905 & .805 & 1.017 \\
\hline Age & -.093 & .060 & 2.354 & 1 & .125 & .911 & .810 & 1.026 \\
\hline Male vs. Female & 1.107 & .164 & 45.575 & 1 & .000 & 3.024 & 2.193 & 4.170 \\
\hline Employed vs. Unemployed & -.413 & .152 & 7.357 & 1 & .007 & .662 & .491 & .892 \\
\hline $\begin{array}{l}\text { Gated vs. non-Gated } \\
\text { Neighbourhoods }\end{array}$ & .337 & .137 & 6.033 & 1 & .014 & 1.401 & 1.070 & 1.833 \\
\hline Constant & -2.193 & .526 & 17.394 & 1 & .000 & .112 & & \\
\hline \multicolumn{9}{|c|}{ Model test Results } \\
\hline \multicolumn{5}{|c|}{ Nagelkerke R Square } & \multicolumn{4}{|c|}{$13.9 \%$} \\
\hline \multicolumn{5}{|c|}{ Percentage Correct } & \multicolumn{4}{|c|}{64.5} \\
\hline
\end{tabular}

\section{Association between NE variables and aggregate PA}

Binary logistic regression was applied to investigate the correlation between NE and socio-demographic parameters and the attainment of the recommended aggregate PA of at least $600 \mathrm{MET} /$ week according to the WHO guidelines. There were total ten parameters which were checked for association with dichotomized (more than $600 \mathrm{MET} /$ week and less than $600 \mathrm{MET} /$ week) aggregate PA. The results show a positive correlation between land-use mix and $600 \mathrm{MET} /$ week aggregate PA with a p-value of 0.015 (CI 1.0-1.6). Street connectivity has also positive association with $600 \mathrm{MET} /$ week aggregate PA, but that association is not statistically significant. Contrariwise, aggregate PA is negatively correlated with housing density with a p-value of 0.003 (CI 0.98-0.99), and this negative correlation is statistically significant. A significant positive correlation exists between PAF and aggregate PA with significant p-value of 0.0001 (CI 1.4-2.6). The results of the analysis of the two hazard perceptions i.e. traffic and crime; and age, and employment status show that these have negative association with aggregate PA. On the other hand, male is more physically active than female with p-value of 0.0001 (CI 2.1-4.1). The aggregate PA in gated neighborhoods was also compared with that in non-gated to investigate the attainment of $600 \mathrm{MET} /$ week in the both types of neighborhoods. The results show that the residents of gated neighborhoods are significantly more physically active than the residents of non-gated neighborhoods with a p-value of 0.014 (CI 1.0-1.8). However, it is also evident from the results that LUM and PAF are the most important indicators which encourage people to be physically active and get recommended aggregate PA (i.e. 
more than $600 \mathrm{MET} /$ week). Therefore, the higher physical activity in the gated neighborhoods can be attributed only to the presence of physical activity facilities in a significantly greater number only as the land-use mix is higher in the non-gated neighborhoods. It has also been found that males, and unemployed persons tend to get more than $600 \mathrm{MET} /$ week as compared to female and employed people, respectively. The overall model percentage of correction was $64.56 \%$, and Nagelkerke R Square (the relations $\mathrm{R}$ value) was $13.9 \%$. The results are summarized in Table 4.

\section{Discussion}

The results show that significant relationships exist between NE and PA in the both of neighborhood types i.e. gated and non-gated. Different indicators have been investigated including the neighborhood built environment, social environment (safety indicators) and the number of physical activity facilities and their association with four types of PA variables, which included vigorous and moderate physical activities as well as practical and recreational walking. The results show that two of the built environment indicators including street connectivity and land-use mix are correlated positively with aggregate walking, but recreational walking is negatively correlated with housing density. These results are consistent with previously reported literature including a study from the USA by Frank et al. [18], a study from Australia by Lesliea et al. [60], a study from Belgium by Van et al. [52], and a study from Sweden by Sundquist et al. [51]. All the above studies reported that physical activity has positive correlation with all the three neighborhood parameters, however, the present study differs from those results in that a negative correlation was found between physical activity and housing density. The contrasting result of housing density with aggregate physical activity is consistent with the results of Zhao [39] who conducted a research in Beijing, China and found that there was negative association between housing density and PA, especially cycling. The results are also consistent with another study from Hong Kong, which investigated the effects of 3D's (design, density, and diversity) on walking and reported that there is association between design and diversity with walking but there is no association between density and walking [42]. The reason for this contrasting result with developed countries and consistent with Beijing and Hong Kong (i.e. case studies of a developing country) is postulated to be that this research was also located in a metropolis of an Asian developing country where the population density is significantly greater than the study areas of those studies conducted in developed countries. The high density encourages many commercial activities in small congested areas, which results in the reduction of PA, especially sports activities and recreational walking.

The availability of physical activity facilities is the most correlated parameter with both the vigorous physical activity and aggregate walking. This result is also consistent with previously reported research by Eriksson et al. [61]. They reported the number of available exercise facilities in $1 \mathrm{~km}^{2}$ buffers around the participant's houses was significantly positively correlated with physical activity. The outcomes of this research are also in agreement with an Iranian study by Shahrokni [62] who reported that a greater number of parks enhances physical activity. The results comparison of the physical activity in gated neighborhoods to that in non-gated neighborhoods shows that the participants from gated neighborhoods are more physically active because there is a higher number of PAF there, consequently, they do more VPA than the participants from non-gated neighborhoods. Whereas, non-gated neighborhoods have more LUM and street connectivity, therefore, people walk more, especially practical walking is more there. This result that gated neighborhoods have less connectivity and more segregation, especially in developing countries, also agrees with a study by Hatipoglu and Mahmut [63] from Turkey.

The results of the analysis of the two hazard perceptions i.e. crime and traffic, show that PA is negatively impacted if any of these hazard perceptions increases, which is in agreement with a study from Nigeria by Oyeyemi et al. [64]. They investigated the effects of neighborhood safety perception on the PA of Nigerian adults, which is a developing country. They determined that a raised hazard perception impedes PA. The present research also concludes that the perception of traffic hazard significantly impacts practical walking. The present study also agrees with the study by Bourdeaudhuij, et al. [65]. Their study reported results from 17 cities from 12 different countries and concluded that the NE parameters were positively correlated with cycling and walking. The present study found the same except that housing density in developing countries impedes PA.

The results of socio-demographics show a negative association of physical activity with age in Karachi, which concur with the findings of Teh, et al., [33] from Malaysia. According to them, despite the fact that $64 \%$ of adults they investigated achieved physical activity requirements, the proportion of people continuing to remain physically active dropped with increasing age. The second important socio-demographic factor investigated here was gender. Unsurprisingly, females were less physically active, which is generally believed to be true in developing countries. Oyeyemi, et al. (2012) also found females to be less physically active in Nigeria. They cited cultural and social restriction being responsible for reduced levels of physical activity among females, especially at night time. It can be assumed relatively confidently that similar social and 
cultural restrictions exist in Karachi. Reza Arjmand [66] studied the effects of the introduction of female exclusive public parks in Iran and found that physical activity in females improved because of the provision of separate parks for females. The results of employment status show that people who are unemployed (including jobless, housekeepers, retired people, or students) are more physically active and get recommended aggregate PA. This is in agreement with a previous research by Ester Cerin [37], who measured employment status through self-reporting and reported the same that unemployed people are more physically active. This is probably because the employed people are physically active at their office places or somewhere else instead of at neighborhood level. The comparison of aggregate PA in gated neighborhoods with that in non-gated shows that the residents of gated neighborhoods are more physically active than non-gated neighborhoods. That is because youngsters do more VPA in gated neighborhoods due to having more PAF there [32].

The strength of this study is that it investigated the relationships of NE indicators and PA variables in Asian developing countries with the study area being Karachi, Pakistan. This study has investigated the most important NE indicators for encouraging PA at neighborhoods level through which one can get a recommended level of PA in a week. This study also compared the physical activity level of people in gated and non-gated neighborhoods from the perspective of developing countries. The use of two methods i.e. objective and perceived with a large sample size is a strength of this study. These findings can be useful to planners and policy makers for incorporating appropriate facilities for physically active neighborhoods in future. Because this study used a cross-sectional method, the results presented here do not reflect any effects that different times of the year (e.g. rising and falling temperatures, rains, etc.) might have on physical activity. The general perception of crime in the study location of the present research is usually higher than developed countries. People in Karachi were did not want to provide data related to their income status. Also, females were generally reluctant to provide any data, therefore, the proportion of female respondents is significantly lower than males. It is also reported in literature that the behavior towards physically challenged persons varies between developed and developing countries [67]. Because of the limited resources and time available, this study could not study the physical activity of physically challenged persons in the study location. Because of these limitations, the generalization of these results to developed countries may not be applicable. Moreover, this study was carried out prior to the onset of the global pandemic of COVID-19. It is possible that the pandemic may also have an effect on the physical activity of people with a possibility of these effects being different in different types of neighborhoods.

\section{Conclusions}

The conclusions of the present study are listed as below:

- There exist correlations between neighborhood environment parameters and physical activity levels in Asian developing countries similar to developed countries all over the world but with some differences.

- The land-use mix is positively correlated to physical activity in both the developed and developing countries.

- The street connectivity is positively correlated to physical activity in both the developed and developing countries.

- The housing density is positively correlated to physical activity in developed countries but in Asian developing countries this correlation is negative.

- The hazard perceptions related to crime and traffic are negatively correlated to physical activity in both the developed and developing countries.

- Gated neighborhoods in Karachi are more physically active because there is a greater number of physical activity facilities there.

- Younger residents (18-30 years) of gated neighborhoods do more vigorous physical activity than older age groups.

- The aggregate walking in gated neighborhoods in Karachi is not higher than non-gated neighborhoods because gated neighborhoods have comparatively lower street connectivity.

- The gated neighborhoods also have lower land-use mix values, which impedes physical activities other than vigorous physical activity.

- Females are less physically active in both the gated and non-gated neighborhoods because of the non-availability of separate physical activity facilities and less walking destinations.

In the light of these results, it is recommended that:

- New policies for neighborhood designs should be formulated in such a way that a specific type of physical activity should not be emphasized such as vigorous physical activity in gated neighborhoods.

- Similarly, the new neighborhood design policies should encourage provision of design features that promote physical activity among all age groups rather than a specific age group.

- The new neighborhood designs in Asian developing countries should focus more on increased street connectivity and a good mix of the land-use rather than gating and isolation.

- Multiple choices should be provided to every individual, such as public parks, openly accessible 
exercise facilities, and female exclusive facilities to encourage physical activity among all groups of the populace.

- There is a need to further study the effects of housing density on physical activity, particularly in mega metropolises of Asian developing countries as it is found that greater housing density discourages physical activity there. However, reducing housing density drastically and suddenly might have grave environmental consequences, which requires further research.

- There is also a need to carry out research as to how the global pandemic has affected the physical activity of the residents of different types of neighborhoods in developing as well as developed countries.

\section{REFERENCES}

[1] World Health Organization, "Global Recommendations on Physical Activity for Health," WHO Library Cataloguing-in-Publication Data, 2010.

[2] U. Eriksson, D. Arvidsson and K. Sundquist, "facilities and physical activity in 2,037 adults: cross-sectional results from the Swedish neighborhood and physical activity (SNAP) study," BMC Public Health, p. 607, 2012.

[3] B. Giles-Corti, A. Timperio, H. Cutt, T. J. Pikora, F. C. Bull, M. Knuiman, m. Bulsara, K. V. Niel and T. Shilton, "Development of a reliable measure of walking within and outside the local neighborhood: RESIDE's Neighborhood Physical Activity Questionnaire," Preventive Medicine, pp. 455-459, 2006.

[4] B. E. Ainsworth, W. L. Haskell, M. C. Whitt, M. L. Irwin, A. M. Swartz, S. J. Strath, W. L. O'brien, D. R. Bassett, k. H. Schmitz, P. O. Emplaincourt, D. R. Jacobs and A. S. Leon, "Compendium of physical activities: an update of activity codes and MET intensities.," Medicine and Science in Sports and Exercise, pp. S498-S504, 2000.

[5] S. Handy, "Community Design and Physical Activity: What Do We Know? - and What DON'T We Know?," Obesity and the Built Environment: Improving Public Health through Community Design, pp. 1-7, 2004.

[6] J. F. Sallis, H. R. Bowles, A. Bauman, B. E. Ainsworth, F. C. Bull, C. L. Craig, M. Sjostrom, I. D. Baurdeaudhuij, J. Lefevre, V. Matsudo and S. Matsudo, "Neighborhood Environments and Physical Activity Among Adults in 11 Countries," American Journal of Preventive Medicine, pp. 484-490, 2009.

[7] J. Dill, N. McNeil, J. Broach and L. Ma, "Bicycle boulevards and changes in physical activity and active transportation: Findings from a natural experiment," Preventive Medicine, vol. 69, pp. 574-578, 2014.

[8] P. J. Troped, J. S. Wilson, C. E. Matthews, E. K. Cromley and S. J. Melly, "The Built Environment and Location-Based Physical Activity," American Journal of
Preventive Medicine, vol. 38, no. 4, pp. 429-438, 2010.

[9] C. Craig, A. L. Marshall, M. SJO, A. E. Bauman, M. L. Booth, B. E. Ainsworth, M. Pratt, U. Ekelund, A. Yngve, J. F. Sallis and P. Oja, "International Physical Activity Questionnaire: 12-Country Reliability and Validity," MEDICINE \& SCIENCE IN SPORTS \& EXERCISE, pp. 1381-1395, 2003.

[10] B. Giles-Corti, A. Timperio, H. Cutt, T. J. Pikora, F. C. Bull, M. Knuiman, m. Bulsara, K. V. Niel and T. Shilton, "Development of a reliable measure of walking within and outside the local neighborhood: RESIDE's Neighborhood Physical Activity Questionnaire," Preventive Medicine, pp. 455-459, 2006.

[11] H. P. v. d. Ploeg, C. Tudor-Locke, A. L. Marshall, C. Craig, M. Hagstromer, M. Sjostrom and A. Bauman, "Reliability and Validity of the International Physical Activity Questionnaire for Assessing Walking," Research Quarterly for Exercise and Sport, p. 97-101, 2010.

[12] S. L. Handy, M. G. Boarnet and R. K. R. E. Ewing, "How the Built Environment Affects Physical Activity: Views from Urban Planning," American Journal of Preventive Medicine, vol. 23, no. 2S, pp. 64-73, 2002.

[13] S. Strath, R. Isaacs and M. J. Greenwald, "Operationalizing Environmental Indicators for Physical Activity in Older Adults," J Aging Phys Act., vol. 15, no. 4, pp. 412-424, October 2007.

[14] K. Sundquist, U. Eriksson, N. Kawakamia, L. Skog and H. Ohlsson, "Neighborhood walkability, physical activity, and walking behavior: The Swedish Neighborhood and Physical Activity (SNAP) study," Social Science and Medicine, pp. 1266-1273, 2011.

[15] J. D. Mackenbach, H. Rutter, S. Compernolle, K. Glonti, J.-M. Oppert, H. Charreire, I. D. Bourdeaudhuij, J. Brug, G. Nijpels and J. Lakerveld, "Obesogenic environments: a systematic review of the association between the physical environment and adult weight status, the SPOTLIGHT project," BMC Public Health, 2014.

[16] J. D. Wineman, R. W. Marans, A. J. Schulz, D. Louis van der Westhuizen, G. B. Mentz and P. Max, "Designing Healthy Neighborhoods: Contributions of the Built Environment to Physical Activity in Detroit," Journal of Planning Education and Research, vol. 34, no. 2, pp. 180-189, 2014.

[17] M. J. Greenwald and M. G. Boarnet, "Built environment as determinant of walking behavior: analyzing nonwork pedestrian travel in Portland, Oregon," Transportation Research Record, pp. 1780, pp. 33-42, 2000.

[18] L. D. Frank, T. L. Schmid, J. F. Sallis, J. Chapman and B. E. Saelens, "Linking Objectively Measured Physical Activity with Objectively Measured Urban Form: Findings from SMARTRAQ," American Journal of Preventive Medicine, vol. 28, no. 2, pp. 117-125, 2005.

[19] J. F. Sallis, H. R. Bowles, A. Bauman, B. E. Ainsworth, F. C. Bull, C. L. Craig, M. Sjostrom, I. De Bourdeaudhuij, J. Lefevre, V. Matsudo, S. Matsudo, D. J. Macfarlane and L. Fernando Gomez, "Neighborhood Environments and Physical Activity Among Adults in 11 Countries," American Journal of Preventive Medicine, vol. 36, no. 6, pp. 484-490, 2009. 
[20] C. P. Durand, M. Andalib, G. F. Dunton, J. Wolch and M. A. Pentz, "systematic review of built environment factors related to physical activity and obesity risk: mplications for smart growth urban planning," obesity reviews, pp. 173-182, 2011.

[21] C. Sarkar, C. Webster and J. Gallacher, "Association between adiposity outcomes and residential density: a full-data, cross-sectional analysis of 419562 UK Biobank adult participants," Lancet Planet Health, pp. 277-288, 2017.

[22] J. Choi, M. Lee, J.-k. Lee, D. Kang and J.-Y. Choi, "Correlates associated with participation in physical activity among adults: a systematic review of reviews and update," BMC Public Health, 2017.

[23] B. Zapata-Diomedi and J. L. Veerman, "The association between built environment features and physical activity in the Australian context: a synthesis of the literature," BMC Public Health, 2016.

[24] M. U. Meyer, C. K. Perry, J. C. Sumrall, M. S. Patterson, S. M. Walsh, S. C. Clendennen, S. P. Hooker, K. R. Evenson, K. V. Goins, K. M. Heinrich, N. O. Tompkins, A. A. Eyler, S. Jones, R. Tabak and C. Valko, "Physical ActivityRelated Policy and Environmental Strategies to Prevent Obesity in Rural Communities: A Systematic Review of the Literature,2002-2013," PREVENTING CHRONIC DISEASE PUBLIC HEALTH RESEARCH, PRACTICE, AND POLICY, 2016.

[25] L. M. S, H. A. A and L. M. Y, "Impact of policy and built environment changes on obesity-related outcomes: a systematic review of naturally occurring experiments," Obesity Reviews, p. 362-375, 2015.

[26] S. Handy, "Community Design and Physical Activity: What Do We Know? - and what DON'T we know," University of California Davis, 2004.

[27] N. L. Bracy, R. A. Millstein, J. A. Carlson, T. L. Conway, J. F. Sallis, B. E. Saelens, J. Kerr, K. L. Cain, L. D. Frank and A. C. King, "Is the relationship between the built environment and physical activity moderated by perceptions of crime and safety?," International Journal of Behavioural Nutrition and Physical Activity, pp. 11-24, 2014.

[28] Y. Gul, Z. Sultan and F. Johar, "Effects of Neighborhood's Built Environment on Physical Activities in Gated Communities: A Review," INTERNATIONAL JOURNAL OF BUILT ENVIRONMENT AND SUSTAINABILITY, vol. 3, no. 1, pp. 60-69, 2016.

[29] E. Cerin, A. Nathan, J. v. Cauwenberg, D. W. Barnett and A. Barnett, "The neighbourhood physical environment and active travel in older adults: a systematic review and meta-analysis," International Journal of Behavioral Nutrition, 2017

[30] M. J. Koohsari, N. Owen, E. Cerin, B. Giles-Corti and T. Sugiyama, "Walkability and walking for transport: characterizing the built environment using space syntax," International Journal of Behavioral Nutrition and Physical Activity, p. 121, 2016.

[31] K. Y. Lee, P. H. Lee and D. Macfarlane, "Associations between Moderate-to-Vigorous Physical Activity and Neighbourhood Recreational Facilities: The Features of the
Facilities Matter," International Journal of Environmental Research and Public Health, vol. 12, no. 11, 2014.

[32] Y. Gul, Z. Sultan, M. Moeinaddini and G. A. Jokhio, "Measuring the differences of neighborhood environment and physical activity in gated and non-gated neighborhoods in Karachi, Pakistan," Journal of Urban Design, 2018.

[33] C. H. Teh, K. K. Lima, Y. Y. Chana, K. H. Lima, O. Azahadi, A. H. Hamizatul Akmara, Y. Ummi Nadiah, M. S. Syafinaz and C. C. Kee, "The prevalence of physical activity and its associated factors among Malaysian adults: Findings from the National Health and Morbidity Survey 2011," Public Health, pp. 416-423, 2014.

[34] J. Kerr, G. Norman, R. Millstein, M. A. Adams, C. Morgan, R. D. Langer and M. Allison, "Neighborhood Environment and Physical Activity Among Older Women: Findings From the San Diego Cohort of the Women's Health Initiative," Journal of Physical Activity \& Health, vol. 11, pp. 1070-1077, 2104.

[35] J. F. Sallis, B. E. Saelens, L. D. Frank, T. L. Conway and D. J. Slymen, "Neighborhood built environment and income: Examining multiple health outcomes," Social Science and Medicine, pp. 1285-1293, 2009.

[36] L. B. Christiansen, E. Cerin, H. Badland, J. Kerr, R. Davey, J. Troelsen, D. V. Dyck, J. Mitáš, G. Schofield, T. Sugiyama, D. Salvo, O. L. Sarmiento, R. Reis, M. Adams, L. Frank and J. J. Sallis, "International comparisons of the associations between objective," Journal of Transport \& Health, p. 467-478, 2016.

[37] E. Cerin, K. L. Cain, T. L. Conway, D. V. Dyck, E. Hinckson, J. Schipperijn, I. D. Bourdeaudhuij, N. Owen, R. C. Davey, A. Akira, F. Hino, J. Mitáš, R. Orzanco-Garralda, D. Salvo, O. L. Sarmiento, L. B. Christiansen, D. J. Macfarlane, G. Schofield and J. F. Sallis, "Neighborhood Environments and Objectively Measured Physical," Med Sci Sports Exerc, p. 2253-2264, 2014.

[38] E. Cerin, C. H. Sit, A. Barnett, M.-c. Cheung and W.-m. Chan, "Walking for Recreation and Perceptions of the Neighborhood Environment in Older Chinese Urban Dwellers," Journal of Urban Health: Bulletin of the New York Academy of Medicine, pp. 56-66, 2012.

[39] P. Zhao, "The Impact of the Built Environment on Bicycle Commuting: Evidence from Beijing," Urban Studies, p. 1019-1037, 2014.

[40] P. Malambo, A. P. Kengne, E. V. Lambert, A. D. Villers and T. Puoane, "Association between perceived built environmental attributes and physical activity among adults in South Africa," BMC Public Health, 2017.

[41] T. Sugiyama, E. Cerin, N. Owen, A. L. Oyeyemi, T. L. Conway, D. V. Dyck and et. al, "Perceived neighbourhood environmental attributes associated with adults' recreational walking: IPEN Adult study in 12 countries," Health and Place, pp. 22-30, 2014.

[42] Y. Lu, Y. Xiao and Y. Ye, "Urban density, diversity and design: Is more always better for walking? A study from Hong Kong," Preventive Medicine, vol. 103, p. 99-S103, 2017.

[43] K. Day, "Built environmental correlates of physical activity in China: A review," Preventive Medicine Reports, p. 303$316,2016$. 
[44] E. J. Blakely and M. G. Snyder, "Divided We Fall: Gated and Walled Communities in the United States," in Architecture of Fear, N. Ellin, Ed., New York, Princeton Architectural Press, 1997.

[45] H. Leisch, "Gated communities in Indonesia," Cities, vol. 19, no. 5, pp. 341-350, 2002.

[46] N. Ahmad, "Choice of Neighbourhoods by Mover Households in Karachi," Urban Studies, pp. 1257-1270, 1993.

[47] Pakistan Bureau of Statistics, "Population size and growth of major cities," Pakistan Bureau of Statistics, Karachi, 1998.

[48] World Atlas, "Populations Of 150 Largest Cities In The World," University of Groningen, Groningen, 2017.

[49] K. Amer, " Population explosion: Put an embargo on industrialisation in Karachi," 06 October 2013. [Online]. Available: http://tribune.com.pk. [Accessed 17 January 2014].

[50] N. Ahmad, "Choice of Neighbourhoods by Mover Households in Karachi," Urban Studies, vol. 30, no. 7, pp. 1257-1270, 1993.

[51] K. Sundquist, U. Eriksson, N. Kawakamia, L. Skog and H. Ohlsson, "Neighborhood walkability, physical activity, and walking behavior: The Swedish Neighborhood and Physical Activity (SNAP) study," Social Science and Medicine, pp. 1266-1273, 2011.

[52] D. D. Van, G. Cardon, B. Deforche, J. F. Sallis, N. Owen and B. I. De, "Neighborhood SES and walkability are related to physical activity behavior in Belgian adults," Prev Med, pp. 50 Suppl 1:S74-9, 2010.

[53] D. Van Dyck, G. Cardon, B. Deforche, J. F. Sallis, N. Owen and I. De Bourdeaudhjij, "Neighborhood SES and walkability are related to physical activity behavior in Belgian adults," Prev Med, pp. 50 Suppl 1:S74-9, 2010.

[54] H. J. Helmerhorst, S. Brage, J. Warren, H. Besson and U. Ekelund, "A systematic review of reliability and objective criterion-related validity of physical," International Journal of Behavioral Nutrition and Physical Activity 2012, p. 103, 2012.

[55] B. Giles-Corti, A. Timperio, H. Cutt, T. J. Pikora, F. C. Bull, M. Knuiman, M. Bulsara, K. V. Niel and T. Shilton, "Development of a reliable measure of walking within and outside the local neighborhood: RESIDE's Neighborhood Physical Activity Questionnaire," Preventive Medicine, pp. 455-459, 2006.

[56] P. Bordoloia, A. Motea, P. P. Sarkarb and C. Mallikarjuna,
"Quantification of Land Use Diversity in The Context of Mixed Land Use," Procedia - Social and Behavioral Sciences, pp. 563-572, 2013.

[57] F. Peiravian, S. Derrible and F. Ijaz, "Development and application of the Pedestrian Environment Index (PEI)," ournal of Transport Geography, pp. 73-84, 2014.

[58] J. M. O. K. H. S. a. M. H. Ann Forsyth, "Does Residential Density Increase Walking and Other Physical Activity?," Urban Studies, pp. 679-697, 2007.

[59] B. E. Saelens and J. F. Sallis, "Neighborhood Environment Walkability Scale (NEWS)," American Journal of Public Health, pp. 78-81, 2002.

[60] E. Lesliea, N. Coffeeb, L. Frank, N. Owend, A. Baumane and G. Hugob, "Walkability of local communities: Using geographic information systems to objectively assess relevant environmental attributes," Health \& Place, pp. 111-122, 2007.

[61] U. Eriksson, D. Arvidsson and K. Sundquist, "Availability of exercise facilities and physical activity in 2,037 adults: cross-sectional results from the Swedish neighborhood and physical activity (SNAP) study," BMC Public Health, p. $607,2012$.

[62] N. Shahrokni, "The Mothers' Paradise: Women-Only Parks and the Dynamics of State Power in the Islamic Republic of Iran," Journal of Middle East Women's Studies, pp. pp. 87-108, 2014.

[63] H. K. Hatipoglu and S. B. Mahmut, "Borders (in between): A City within a City Decoding Different Morpholigies of Fragmented Housing," Civil Engineering and Architecture, vol. 8, no. 5, pp. 880-889, 2020.

[64] L. A. Oyeyemi, F. J. Sallis, D. Benedicte, A. Y. Oyeyemi, I. D. Bourdeaudhuij and D. V. Dyck, "Evaluation of the neighborhood environment walkability scale in Nigeria.," International journal of health geographics, p. 16, 2013.

[65] I. D. Bourdeaudhuij, D. V. Dyck, D. Slavo, R. Davey, R. S. Reis and G. Schofield, "International study of perceived neighbourhood environmental attributes and Body Mass Index: IPEN adult study in 12 countries," International Journal of Behavioural Nutrition and Physical Acitivity, 2015.

[66] R. Arjmand, Public Urban Space, Gender and Segregation, Women-only Parks in Iran, Routledge, 2016.

[67] F. Saito, H. Yamashita, M. Shrestha and M. Goto, "An investigation into Attitudes toward Physically Challenged Persons in Nepal: A Comparative study with Japan," Environment and Ecology Research, vol. 8, no. 2, pp. 29-40, 2020. DOI: 10.13189/eer.2020.080201. 